\title{
The undecidability of propositional adaptive logic
}

\author{
Leon Horsten • Philip Welch
}

Published online: 24 March 2009

(C) Springer Science+Business Media B.V. 2009

\section{Erratum to: Synthese (2007) 158, 41-60 DOI 10.1007/s11229-006-9049-5}

In Horsten and Welch (2007) we discussed two systems of propositional adaptive logic of Batens et al. These are systems of formal consequence based on various rules or strategies for forming proofs; we focused on the reliability and the minimal abnormality strategies. The aim of our paper was to be diagnostic of the complexity of these paraconsistent logics, and to see, e.g. (a) whether, like classical systems, one had recursively enumerable consequence sets. In particular we wished to investigate (b) the claim that as a proof developed one obtained better approximations to a final consequence (cf. Batens 2001, p. 63). As lower bounds we proved there that the final consequence set from a set of recursive hypotheses $\Gamma$ could be $\Sigma_{3}^{0}$-complete using either of the above strategies and was thus remote from recursively enumerable. As upper bounds we classified the first system using the reliability strategy as always yielding $\Sigma_{3}^{0}$ consequence sets, and the second system as having $\Pi_{1}^{1}$ consequence sets. Thus for the reliability strategy this was best possible.

We then claimed (erroneously) that the complexity of the minimal abnormality strategy set could also be reduced from $\Pi_{1}^{1}$ to $\Sigma_{3}^{0}$. Paul Verdée has recently argued in

The online version of the original article can be found under doi:10.1007/s11229-006-9049-5.

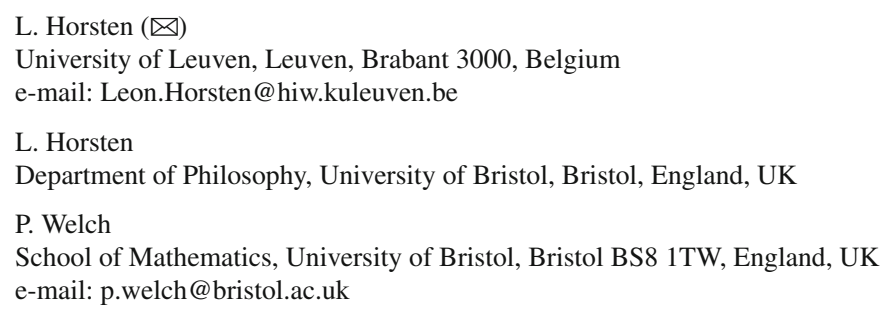


this journal (Verdée 2008) that it is after all $\Pi_{1}^{1}$-hard. This alerted us to an error [it is located at $(\Leftarrow)$ in our Lemma 1$]$, and we are very grateful to him for this warning.

Although this would make the final consequence set for this second logic yet more complicated, it does not affect our investigation (b) of the claim that as a proof developed one obtained somehow better approximations to final consequence. For this to happen we should have had to obtain a $\Delta_{2}^{0}$ classification at worst (as a form of "truthin-the-limit"). For neither logic did this turn out to be the case, as our original calculation showed, since for these purposes $\Sigma_{3}^{0}$-hardness amply sufficed. Verdée speaks for us in Verdée (2008) concerning his $\Pi_{1}^{1}$-hardness result “...they [Horsten and Welch] would probably see this as an even bigger problem for adaptive logics ..."

\section{References}

Batens, D. (2001). A general characterization of adaptive logics. Logique et Analyse, 173-175, 45-68.

Horsten, L., \& Welch, P. D. (2007). The undecidability of propositional adaptive logic. Synthese, 158(1), 41-60.

Verdée, P. (2008). Propositional adaptive logics using the minimal abnormality strategy are $\Pi_{1}^{1}$ complex. Synthese. 